\title{
A Thermodynamic Study on the Binding of Cobalt(II) and Iron(III) Ions with Bovine Carbonic Anhydrase II at Different Temperatures
}

\author{
G. Rezaei Behbehani • A. Divsalar • A.A. Saboury • \\ R. Hajian · Z. Rezaei · E. Yahaghi · L. Barzegar
}

Received: 12 August 2009 / Accepted: 22 March 2010 / Published online: 26 August 2010

(C) The Author(s) 2010. This article is published with open access at Springerlink.com

\begin{abstract}
A thermodynamic study on the interaction of bovine carbonic anhydrase II, CAII, with cobalt(II) and iron(III) ions was made using isothermal titration calorimetry (ITC) at $300.15 \mathrm{~K}$ and $310.15 \mathrm{~K}$ in Tris buffer solutions at $\mathrm{pH}=7.5$. The enthalpies of interaction of $\mathrm{Co}^{2+}+\mathrm{CAII}$ and $\mathrm{Fe}^{3+}+\mathrm{CAII}$ are reported and analyzed in terms of the extended solvation theory. The results indicate that there are three identical and non-cooperative binding sites for $\mathrm{Co}^{2+}$ and $\mathrm{Fe}^{3+}$ ions. Binding of these ions with CAII occurs exothermically with dissociation equilibrium constants of 87.15 and $91.00 \mu \mathrm{mol} \cdot \mathrm{L}^{-1}$ at $300.15 \mathrm{~K}$, for $\mathrm{Co}^{2+}$ and $\mathrm{Fe}^{3+}$, respectively.
\end{abstract}

Keywords Bovine carbonic anhydrase · Cobalt ion · Isothermal titration calorimetry

\section{Introduction}

Carbonic anhydrases, CA, are ubiquitous zinc enzymes that are present in archaea, prokaryotes and eukaryotes, which are encoded by three distinct, evolutionarily unrelated, genetic

G. Rezaei Behbehani $(\bowtie)$

Chemistry Department, Imam Khomeini International University, Qazvin, Iran e-mail: grb402003@yahoo.com

A. Divsalar · A.A. Saboury

Institute of Biochemistry and Biophysics, University of Tehran, Tehran, Iran

A. Divsalar

Department of Biological Sciences, Tarbiat Moallem University, Tehran, Iran

R. Hajian · Z. Rezaei

Department of Chemistry, Islamic Azad University, Gachsaran, Iran

E. Yahaghi

School of Chemistry, University of Tehran, Tehran, Iran

L. Barzegar

Department of Chemistry, Payam Noor University (PNU), Abhar, Iran

글 Springer 
families, and occur as $\alpha$-CA, $\beta$-CA and $\gamma$-CA forms [1-4]. CA is one of the fastest acting enzymes known, with a maximal turnover rate for $\mathrm{CO}_{2}$ hydration of $\sim 10^{6} \mathrm{~s}^{-1}$ at $25^{\circ} \mathrm{C}$, which is probably the reason why the activation of CA has not been much studied. In contrast, inhibition of CA has been widely investigated and crystal structures have been reported of several CA complexes with inhibitor molecules [1, 5].

CAII is a novel metallo protein due to its unusually high affinity for zinc(II), whose CAII $+\mathrm{Zn}^{2+}$ dissociation constant is $1-10 \mathrm{pmol} \cdot \mathrm{L}^{-1}$ [1]. The role of highly conserved aromatic residues surrounding the zinc-binding site of human carbonic anhydrase II (CAII), in determining the metal ion binding specificity of this enzyme, has been previously examined using mutagenesis [6, 7]. Residues F93, F95, and W97 are located along a $\beta$-strand containing two residues that coordinate zinc, $\mathrm{H} 94$ and $\mathrm{H} 96$, and these aromatic amino acids contribute to the high zinc affinity and slow rate constant for dissociation of $\mathrm{Zn}$ (II) from CAII. Substitution of these aromatic amino acids with smaller side chains enhances the affinity for copper (up to 100 fold) while decreasing the affinity for both cobalt and zinc, thereby altering the metal ion binding specificity by as much as a factor of $10^{4}$. Furthermore, the Gibbs energy for stabilization of native CAII, determined by solvent-induced denaturation, correlates positively with the increased hydrophobicity of the amino acids at positions 93, 95, and 97, as well as with affinities for $\mathrm{Co}(\mathrm{II})$ and $\mathrm{Zn}$ (II) $[8,9]$. Conversely, an increased affinity for $\mathrm{Cu}$ (II) correlates with decreased protein stability. Although CAII is loaded with $\mathrm{Zn}(\mathrm{II})$ in its physiologically relevant condition, it can also bind a number of other divalent metal ions at the zinc binding site including $\mathrm{Co}^{2+}, \mathrm{Ni}^{2+}, \mathrm{Cu}^{2+}, \mathrm{Cd}^{2+}, \mathrm{Hg}^{2+}$ and $\mathrm{Pb}^{2+}$ but with different affinities $[4,7]$.

Some $\mathrm{Zn}$ (II) and $\mathrm{Cu}$ (II) metal complexes of sulfonamides that incorporate polyaminopolycarboxylated tails have also been reported, which indeed show very good in vitro inhibitory activity against the isoforms CA I, II, and IV [7, 8]. In this paper, the effects of $\mathrm{Co}(\mathrm{II})$ and $\mathrm{Fe}(\mathrm{III})$ ions on the structure and stability of CAII are examined.

\section{Materials and Method}

Erythrocyte bovine carbonic anhydrase was obtained from Sigma. Copper sulfate was obtained from Merck. The buffer solution used in the experiments, which was $50 \mathrm{mmol} \cdot \mathrm{L}^{-1}$ Tris, $\mathrm{pH}=7.5$, was obtained from Merck.

All of the calorimetry experiments were carried out in $300.15 \mathrm{~K}$ and $310.15 \mathrm{~K}$. The experiments were performed with a 4-channel commercial microcalorimetric system, Thermal Activity Monitor 2277 (Thermometric, Sweden). Each channel is a twin heat-conduction calorimeter (multijunction thermocouple plates), positioned between the vessel holders and the surrounding heat sink. Both sample and reference vessels are made from stainless steel. The limiting sensitivity of the calorimeter is $0.4 \mu \mathrm{J}$. Cobalt(II) nitrate solution $\left(5 \mathrm{mmol} \cdot \mathrm{L}^{-1}\right)$ was injected by use of a Hamilton syringe into the calorimetric titration vessel, which contained $1.8 \mathrm{~mL}$ of $30 \mu \mathrm{mol} \cdot \mathrm{L}^{-1} \mathrm{CA}$ solution, in the Tris buffer $\left(30 \mathrm{mmol} \cdot \mathrm{L}^{-1}\right)$ at $\mathrm{pH}=7.5$. Thin $(0.15 \mathrm{~mm}$ inner diameter) stainless steel hypodermic needles, permanently fixed to the syringe, reach directly into the calorimetric vessel. Injection of $20 \mu \mathrm{L}$ metal nitrate samples into the perfusion vessel was repeated 30 times. The calorimetric signal was measured with a digital voltmeter that was part of a computerized recording system. The heat of injection was calculated with the "Thermometric Digitam 3" software program. The heats of dilution of $\mathrm{Co}$ (II) and $\mathrm{Fe}$ (III) nitrate solution were measured as described above except that CAII was absent. Also, the enthalpy of dilution of the protein solution was measured as described above, except that buffer solution was injected into the protein solution in the sample cell. The enthalpies of dilution of $\mathrm{Co}\left(\mathrm{NO}_{3}\right)_{2}, \mathrm{Fe}\left(\mathrm{NO}_{3}\right)_{3}$ and protein solutions were subtracted 
Table 1 The heats of $\mathrm{Co}^{2+}+\mathrm{CAII}$ interactions, $q$, at $300 \mathrm{~K}$ and $310 \mathrm{~K}$, where the $q_{\text {dilut }}$ are heats of dilution of $\mathrm{Co}\left(\mathrm{NO}_{3}\right)_{2}$ with water. The precision of the measurements is $\pm 0.1 \mu \mathrm{J}$ or better

\begin{tabular}{|c|c|c|c|c|c|}
\hline$\left[\mathrm{Co}^{2+}\right] / \mathrm{mM}$ & {$[\mathrm{CAII}] / \mu \mathrm{mol} \cdot \mathrm{L}^{-1}$} & $q^{\mathrm{a}} / \mu \mathrm{J}$ & $q_{\text {dilut }}{ }^{\mathrm{a}} / \mu \mathrm{J}$ & $q^{\mathrm{b}} / \mu \mathrm{J}$ & $q_{\text {dilut }} \mathrm{b} / \mu \mathrm{J}$ \\
\hline 0.055 & 29.670 & -635.3 & -424.8 & -563.5 & -398.3 \\
\hline 0.109 & 29.348 & -1065.4 & -790.4 & -954.2 & -742 \\
\hline 0.161 & 29.032 & -1350.6 & -1089.6 & -1222.6 & -1021.5 \\
\hline 0.213 & 28.723 & -1543.7 & -1344 & -1410.7 & -1260 \\
\hline 0.263 & 28.421 & -1679.4 & -1562.4 & -1546.7 & -1464.7 \\
\hline 0.312 & 28.125 & -1778.5 & -1740 & -1648.3 & -1631.2 \\
\hline 0.361 & 27.835 & -1853.4 & -1895.2 & -1726.5 & -1776.7 \\
\hline 0.408 & 27.551 & -1911.7 & -2028.8 & -1788.2 & -1902 \\
\hline 0.454 & 27.273 & -1958.2 & -2140.8 & -1838 & -2008 \\
\hline 0.500 & 27.000 & -1996.1 & -2232 & -1879 & -2092.5 \\
\hline 0.544 & 26.733 & -2027.6 & -2316.5 & -1913.2 & -2171.3 \\
\hline 0.588 & 26.470 & -2054.1 & -2390.1 & -1942.2 & -2240.3 \\
\hline 0.631 & 26.214 & -2076.7 & -2456.5 & -1967.1 & -2302.5 \\
\hline 0.673 & 25.962 & -2096.2 & -2510.9 & -1988.6 & -2353.5 \\
\hline 0.714 & 25.714 & -2113.2 & -2561.8 & -2007.4 & -2401.7 \\
\hline 0.755 & 25.472 & -2128.1 & -2605 & -2024 & -2442.2 \\
\hline 0.794 & 25.233 & -2141.3 & -2644.8 & -2038.8 & -2479.7 \\
\hline 0.833 & 25.000 & -2153.1 & -2681.6 & -2052 & -2513.2 \\
\hline 0.872 & 24.771 & -2163.7 & -2715.2 & -2063.9 & -2544.7 \\
\hline 0.909 & 24.545 & -2173.2 & -2745 & -2074.6 & -2572.4 \\
\hline 0.946 & 24.324 & -2181.8 & -2771.4 & -2084.3 & -2597.2 \\
\hline 0.982 & 24.107 & -2189.7 & -2794.8 & -2093.2 & -2618.9 \\
\hline 1.018 & 23.894 & -2196.9 & -2816.4 & -2101.3 & -2640.2 \\
\hline 1.053 & 23.684 & -2203.5 & -2836.2 & -2108.8 & -2658.9 \\
\hline 1.087 & 23.478 & -2209.6 & -2854.6 & -2115.7 & -2676.6 \\
\hline 1.121 & 23.276 & -2215.2 & -2870.4 & -2122.1 & -2691.6 \\
\hline
\end{tabular}

${ }^{\mathrm{a}}$ At $300 \mathrm{~K}$

${ }^{\mathrm{b}}$ At $310 \mathrm{~K}$

from the heats of $\mathrm{Co}\left(\mathrm{NO}_{3}\right)_{2}$ and $\mathrm{Fe}\left(\mathrm{NO}_{3}\right)_{3}$ in CAII solutions. The measured heats for $\mathrm{Co}^{2+}+$ CAII and $\mathrm{Fe}^{3+}+$ CAII interactions are listed in Tables 1 and 3 (in $\mu \mathrm{J}$ ). The microcalorimeter was frequently calibrated electrically during the course of the study.

\section{Results and Discussion}

It has been shown previously [8-12] that the enthalpies of interaction of biopolymers with ligands in aqueous solutions can be reproduced with the following equation

$$
q=q_{\max } x_{\mathrm{B}}^{\prime}-\delta_{\mathrm{A}}^{\theta}\left(x_{\mathrm{A}}^{\prime} L_{\mathrm{A}}+x_{\mathrm{B}}^{\prime} L_{\mathrm{B}}\right)-\left(\delta_{\mathrm{B}}^{\theta}-\delta_{\mathrm{A}}^{\theta}\right)\left(x_{\mathrm{A}}^{\prime} L_{\mathrm{A}}+x_{\mathrm{B}}^{\prime} L_{\mathrm{B}}\right) x_{\mathrm{B}}^{\prime}
$$

The parameters $\delta_{\mathrm{A}}^{\theta}$ and $\delta_{\mathrm{B}}^{\theta}$ are measures of the CAII stability as a result of interaction with a metal ion, $L$, at low and high metal ions concentration, respectively. If the binding of 
Fig. 1 Comparison of the experimental heats for $\mathrm{Co}^{2+}+$ CAII interactions at $300 \mathrm{~K}(\mathrm{O})$ and $310 \mathrm{~K}(\square)$ with calculated results (lines) via Eq. 1; "mM" denotes concentration units of $\mathrm{mmol} \cdot \mathrm{L}^{-1}$

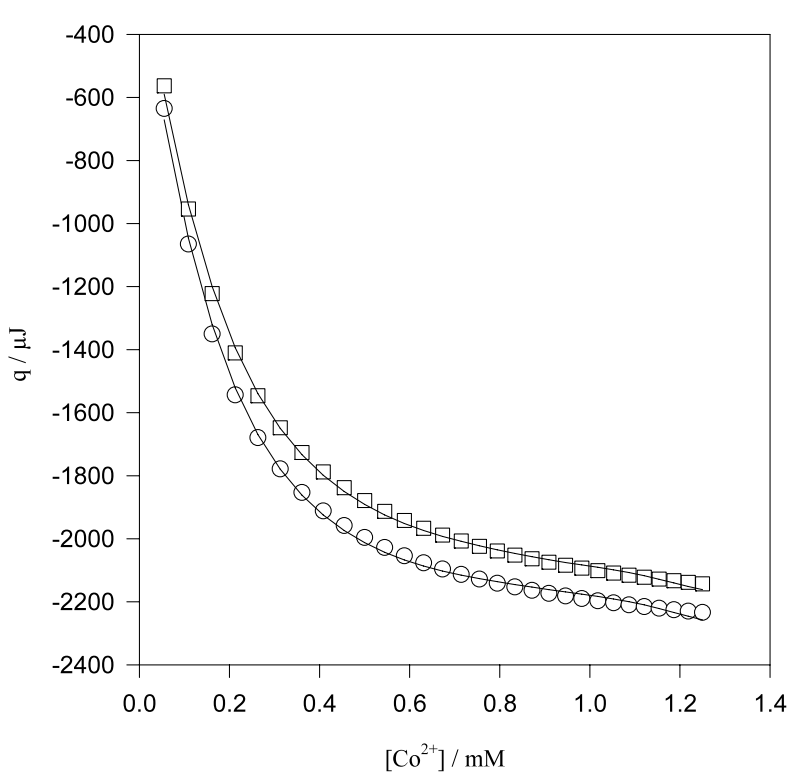

ligand at one site increases the affinity for this ligand at another site, then the macromolecule exhibits positive cooperativity. Conversely, if the binding of ligand at one site lowers the affinity for the ligand at another site, then the protein exhibits negative cooperativity. If the ligand binds at each site independently, then the binding is non-cooperative. Values of $p<1$ or $p>1$ indicate positive or negative cooperativity for binding of a macromolecule with metal ion ligand, respectively, whereas $p=1$ indicates that the binding is non-cooperative. $x_{\mathrm{B}}^{\prime}$ can be expressed as follows:

$$
x_{\mathrm{B}}^{\prime}=\frac{p x_{\mathrm{B}}}{x_{\mathrm{A}}+p x_{\mathrm{B}}}
$$

where $x_{\mathrm{B}}^{\prime}$ is the fraction of the metal ions $\left(\mathrm{Co}^{2+}\right.$ or $\left.\mathrm{Fe}^{3+}\right)$ bound to the sites on CAII, and $x_{\mathrm{A}}^{\prime}=1-x_{\mathrm{B}}^{\prime}$ is the fraction of the unbound ("free") metal ions $\left(L_{\mathrm{F}}\right)$. We can express $x_{\mathrm{B}}$ in terms of the total metal ion concentration, $L_{\mathrm{T}}$, divided by the maximum concentration of the metal ion upon saturation of all CAII binding sites, $L_{\max }$, as follows:

$$
x_{\mathrm{B}}=\frac{L_{\mathrm{T}}}{L_{\max }}, \quad x_{\mathrm{A}}=1-x_{\mathrm{B}}
$$

$L_{\mathrm{A}}$ and $L_{\mathrm{B}}$ are the relative contributions of unbound and bound $\mathrm{Co}^{2+}$ or $\mathrm{Fe}^{3+}$ to the enthalpies of dilution when CAII is absent and can be calculated from the enthalpies of dilution of $\mathrm{Co}^{2+}$ or $\mathrm{Fe}^{3+}$ in the buffer, $q_{\text {dilut }}$, as follows:

$$
L_{\mathrm{A}}=q_{\text {dilut }}+x_{\mathrm{B}}\left(\frac{\partial q_{\text {dilut }}}{\partial x_{\mathrm{B}}}\right), \quad L_{\mathrm{B}}=q_{\text {dilut }}-x_{\mathrm{A}}\left(\frac{\partial q_{\text {dilut }}}{\partial x_{\mathrm{B}}}\right)
$$

The heats of $L+$ CAII interactions, $q$, were fitted to Eq. 1 . In the fitting procedure, only the adjustable parameter $p$ was changed until the best agreement was obtained between the experimental and calculated data (Figs. 1 and 4 ). The optimized $\delta_{\mathrm{A}}^{\theta}$ and $\delta_{\mathrm{B}}^{\theta}$ values are recovered from the coefficients of the second and third terms of Eq. 1. The agreement between 
Fig. 2 Comparison of experimental Gibbs energies at $300 \mathrm{~K}(\Delta)$ and $310 \mathrm{~K}(\boldsymbol{\Delta})$ for $\mathrm{Co}^{2+}+\mathrm{CAII}$ interactions and calculated results (lines) via Eqs. 7 and 8; mM denotes concentration units of $\mathrm{mmol} \cdot \mathrm{L}^{-1}$. The linearity of $\Delta G$ as a function of the $\mathrm{Co}^{2+}$ concentration a lower concentrations indicates that the structural effects compensate each other in the Gibbs energy, which supports the extended solvation model



calculated and experimental results (Fig. 1) is excellent and gives considerable support to the use of Eq. 1.

$\Phi$ is the fraction of CAII molecules undergoing complexation with $\mathrm{Co}^{2+}$ or $\mathrm{Fe}^{3+}$, which can be expressed as follows:

$$
\Phi=\frac{q}{q_{\max }}
$$

where $q_{\max }$ represents the heat value obtained when all CAII binding sites are saturated. The apparent equilibrium constant, $K_{a}$, as a function of the free concentration of metal ion, $L_{\mathrm{F}}$, is given by the following equation:

$$
K_{a}=\frac{\Phi}{(1-\Phi) L_{\mathrm{F}}}=\frac{\Phi}{(1-\Phi) L_{\mathrm{T}}\left(1-x_{\mathrm{B}}\right)}
$$

The Gibbs energies as a function of ligand concentrations can be calculated from:

$$
\Delta G=-R T \ln K_{a}
$$

Values of $\Delta G$, calculated from Eq. 7 at different temperatures, are shown graphically in Figs. 2 and 5. The $\Delta S$ values were calculated from the $\Delta G$ values at different temperatures and are shown in Figs. 3 and 6. The linearity of $\Delta G$ against $\mathrm{Co}^{2+}$ and $\mathrm{Fe}^{3+}$ concentrations indicates that structural effects compensate each other in the Gibbs energy, which supports the use of the extended solvation model.

Consider a solution containing a ligand $\left(\mathrm{Co}^{2+}\right.$ or $\left.\mathrm{Fe}^{3+}\right)$ and a macromolecule (CAII in this case) that contains $g$ sites capable of binding the ligand. If the multiple binding sites on a macromolecule are identical and independent, then the ligand binding sites can be analyzed by a model system of monomeric molecules $\left\{(\mathrm{CAII})_{g} \rightarrow g(\mathrm{CAII})\right\}$ having the same set of 
Fig. 3 Comparison between the experimental entropies at $300 \mathrm{~K}$ $(\Delta)$ and $310 \mathrm{~K}(\Delta)$ for $\mathrm{Co}^{2+}+$ CAII interactions and calculated results (lines) via Eqs. 7 and 8; $\mathrm{mM}$ denotes concentration units of $\mathrm{mmol} \cdot \mathrm{L}^{-1}$

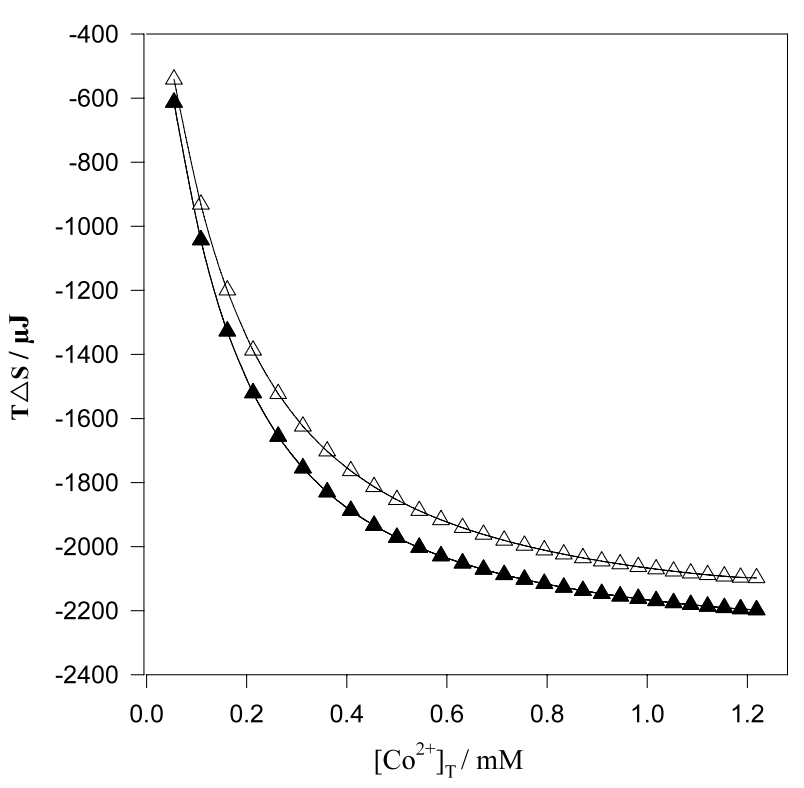

dissociation equilibrium constant, $K_{\mathrm{d}}$, values. Thus, the reaction can be written as:

$$
\mathrm{M}+\mathrm{L} \rightleftharpoons \mathrm{ML} \quad K_{\mathrm{d}}=\frac{[\mathrm{M}][\mathrm{L}]}{[\mathrm{ML}]}
$$

If $\alpha$ is defined as the fraction of free binding sites on the biomacromolecule, $M_{0}$ the total biomacromolecule concentration, and $L_{0}$ the total ligand concentration, then the free concentrations of monomeric molecule $[\mathrm{M}]$ and ligand $[\mathrm{L}]$ as well as the concentration of bound ligand $[\mathrm{ML}]$ can be deduced as follows:

$$
\begin{aligned}
{[\mathrm{ML}] } & =g(1-\alpha) M_{0} \\
{[\mathrm{~L}] } & =L_{0}-[\mathrm{ML}]=L_{0}-g(1-\alpha) M_{0}, \\
{[\mathrm{M}] } & =g M_{0}-[\mathrm{ML}]=g M_{0}-g(1-\alpha) M_{0}=\alpha g M_{0}
\end{aligned}
$$

Substitution of free concentrations of all these components in Eq. 8 gives:

$$
K_{\mathrm{d}}=\left(\frac{\alpha}{1-\alpha}\right) L_{0}-\alpha g M_{0}
$$

or

$$
\alpha M_{0}=\left(\frac{\alpha}{1-\alpha}\right)\left(\frac{1}{g}\right) L_{0}-\frac{K_{\mathrm{d}}}{g}
$$

Here $1-\alpha$ is the fraction of occupied binding sites on the biomacromolecule:

$$
1-\alpha=\frac{q}{q_{\max }}
$$

where $q$ represents the heat value at a certain ligand concentration $L_{0}$, and $q_{\max }$ represents the heat value upon saturation of all biomacromolecule with ligands. If $q$ and $q_{\max }$ are cal- 
Table 2 Binding parameters for $\mathrm{Co}^{2+}+\mathrm{CAII}$ interactions via Eq. 1 . A value of $p=1$ implies that $\mathrm{Co}^{2+}$ binds non-cooperatively to the native CAII structure. The positive values of $\delta_{\mathrm{B}}^{\theta}$ imply that specific interactions, defined here as preferential interactions between $\mathrm{Co}^{2+}$ ion and the native folded state of CAII, are dominant

\begin{tabular}{lll}
\hline Binding parameters & $T=300.15 \mathrm{~K}$ & $T=310.15 \mathrm{~K}$ \\
\hline$K_{1} / \mu \mathrm{mol} \cdot \mathrm{L}^{-1}$ & $87.150 \pm 0.016$ & $105.084 \pm 0.012$ \\
$K_{2} / \mu \mathrm{mol} \cdot \mathrm{L}^{-1}$ & $87.150 \pm 0.016$ & $105.084 \pm 0.012$ \\
$K_{3} / \mu \mathrm{mol} \cdot \mathrm{L}^{-1}$ & $87.150 \pm 0.016$ & $105.084 \pm 0.012$ \\
$p$ & $1 \pm 0.004$ & $1 \pm 0.002$ \\
$\delta_{\mathrm{A}}^{\theta}$ & $0.006 \pm 0.001$ & $-0.083 \pm 0.016$ \\
$\delta_{\mathrm{B}}^{\theta}$ & $3.680 \pm 0.031$ & $3.305 \pm 0.021$ \\
$\Delta H_{\mathrm{bin}} / \mathrm{kJ} \cdot \mathrm{mol}^{-1}$ & $-22.204 \pm 0.034$ & $-21.602 \pm 0.012$ \\
$g$ & 3 & 3 \\
\hline
\end{tabular}

Fig. 4 Comparison of the experimental heats for $\mathrm{Fe}^{3+}+$ CAII interactions at $300.15 \mathrm{~K}(\mathrm{O})$ and $310.15 \mathrm{~K}(\square)$ and calculated results (lines) via Eq. 1; $\mathrm{mM}$ denotes concentrations in units of $\mathrm{mmol} \cdot \mathrm{L}^{-1}$

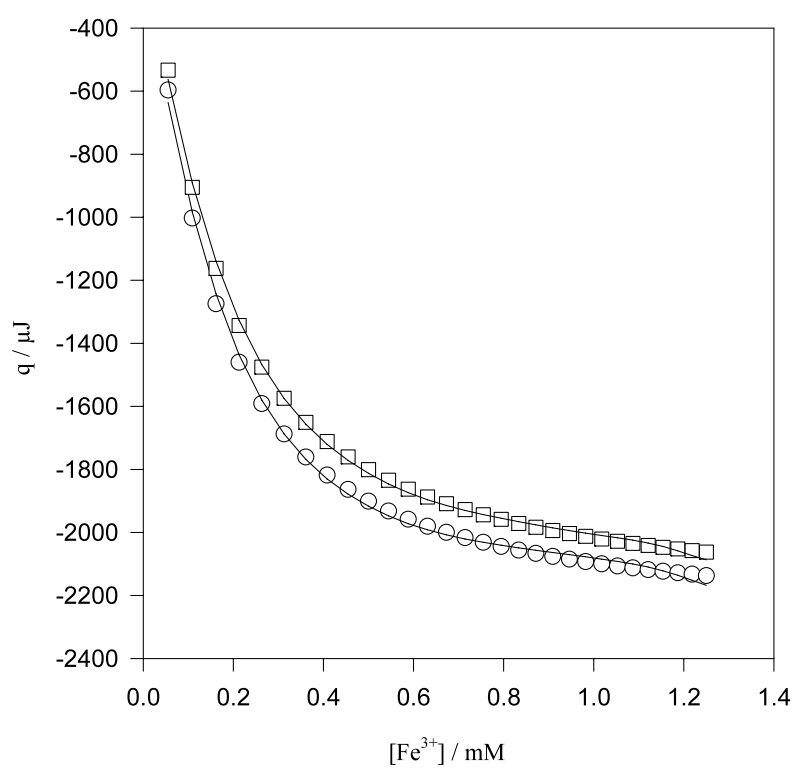

culated per mole of biomacromolecule, then the molar enthalpy of binding for each binding site $\left(\Delta H_{\text {bin }}\right)$ is given by:

$$
\Delta H_{\mathrm{bin}}=\frac{q_{\max }}{g}
$$

Combining Eqs. 13 and 14 yields:

$$
\left(\frac{\Delta q}{q_{\max }}\right) M_{0}=\frac{\Delta q}{q} L_{0}\left(\frac{1}{g}\right)-\frac{K_{\mathrm{d}}}{g}
$$

where $\Delta q=q_{\max }-q$. Therefore, a plot of $\left(\frac{\Delta q}{q_{\max }}\right) M_{0}$ versus $\left(\frac{\Delta q}{q}\right) L_{0}$ should be linear with a slope of $\frac{1}{g}$ and a vertical intercept of $\frac{K_{\mathrm{d}}}{g}$. 
Table 3 The heats of $\mathrm{Fe}^{3+}+\mathrm{CAII}$ interactions, $q$, at $300 \mathrm{~K}$ and $310 \mathrm{~K}$, where the $q$ dilut are heats of dilution of $\mathrm{Fe}\left(\mathrm{NO}_{3}\right)_{3}$ with water. The precision is $\pm 0.1 \mu \mathrm{J}$ or better

\begin{tabular}{|c|c|c|c|c|c|}
\hline$\left[\mathrm{Fe}^{3+}\right] / \mu \mathrm{mol} \cdot \mathrm{L}^{-1}$ & {$[\mathrm{CAII}] / \mu \mathrm{mol} \cdot \mathrm{L}^{-1}$} & $q^{\mathrm{a}} / \mu \mathrm{J}$ & $q_{\text {dilut }} \mathrm{a} / \mu \mathrm{J}$ & $q^{\mathrm{b}} / \mu \mathrm{J}$ & $q_{\text {dilut }} \mathrm{b} / \mu \mathrm{J}$ \\
\hline 54.945 & 29.670 & -596.6 & -382.6 & -553.6 & -358.7 \\
\hline 108.696 & 29.348 & -1002.8 & -711.9 & -905.4 & -668.3 \\
\hline 161.290 & 29.032 & -1274.5 & -981.5 & -1162.5 & -920.1 \\
\hline 212.766 & 28.723 & -1460 & -1210.7 & -1343.9 & -1135.0 \\
\hline 263.158 & 28.421 & -1591.3 & -1407.5 & -1475.8 & -1319.5 \\
\hline 312.500 & 28.125 & -1687.7 & -1567.6 & -1574.7 & -1469.6 \\
\hline 360.825 & 27.835 & -1760.9 & -1707.5 & -1651.1 & -1600.8 \\
\hline 408.163 & 27.551 & -1818 & -1828 & -1711.6 & -1713.8 \\
\hline 454.545 & 27.273 & -1863.7 & -1929.1 & -1760.5 & -1809.5 \\
\hline 500.000 & 27.000 & -1901 & -2011.4 & -1800.5 & -1885.8 \\
\hline 544.554 & 26.733 & -1932 & -2087.7 & -1834.5 & -1957.0 \\
\hline 588.2352 & 26.470 & -1958.2 & -2154.2 & -1863.1 & -2019.5 \\
\hline 631.068 & 26.213 & -1980.5 & -2214.2 & -1887.7 & -2075.6 \\
\hline 673.077 & 25.961 & -1999.8 & -2263.4 & -1909.0 & -2121.8 \\
\hline 714.286 & 25.714 & -2016.6 & -2309.5 & -1927.6 & -2165.4 \\
\hline 754.717 & 25.472 & -2031.4 & -2348.6 & -1944.1 & -2202.2 \\
\hline 794.392 & 25.234 & -2044.5 & -2384.7 & -1958.7 & -2236.2 \\
\hline 833.333 & 25.000 & -2056.2 & -2418.1 & -1971.8 & -2266.6 \\
\hline 871.559 & 24.770 & -2066.7 & -2448.6 & -1983.6 & -2295.2 \\
\hline 909.091 & 24.545 & -2076.2 & -2475.7 & -1994.2 & -2320.4 \\
\hline 945.946 & 24.324 & -2084.8 & -2499.7 & -2003.9 & -2343.0 \\
\hline 982.143 & 24.107 & -2092.6 & -2521 & -2012.7 & -2362.8 \\
\hline 1017.699 & 23.894 & -2099.8 & -2540.7 & -2020.8 & -2382.2 \\
\hline 1052.631 & 23.684 & -2106.4 & -2558.8 & -2028.2 & -2399.3 \\
\hline 1086.956 & 23.478 & -2112.5 & -2575.6 & -2035.0 & -2415.5 \\
\hline 1120.690 & 23.276 & -2118.1 & -2590.1 & -2041.3 & -2429.3 \\
\hline 1153.846 & 23.077 & -2123.3 & -2603.3 & -2047.2 & -2442.0 \\
\hline 1186.441 & 22.881 & -2128.1 & -2614.4 & -2052.7 & -2452.4 \\
\hline 1218.487 & 22.689 & -2132.6 & -2624.8 & -2057.8 & -2462.4 \\
\hline 1250.000 & 22.500 & -2136.8 & -2633.7 & -2062.6 & -2470.9 \\
\hline
\end{tabular}

${ }^{\mathrm{a}}$ At $300 \mathrm{~K}$

${ }^{\mathrm{b}}$ At $310 \mathrm{~K}$

The linearity of the plot was examined by varying the estimated values for $q_{\max }$ to yield a fit with the best value for the correlation coefficient. The best linear plot with the correlation coefficient value $\left(r^{2} \approx 1\right)$ was obtained using $-2398 \mu \mathrm{J}$ and $-2333 \mu \mathrm{J}$, equal to $-22.204 \mathrm{~kJ} \cdot \mathrm{mol}^{-1}$ and $-21.602 \mathrm{~kJ} \cdot \mathrm{mol}^{-1}$ at $300.15 \mathrm{~K}$ and $310.15 \mathrm{~K}$, respectively. The values of $g$ and $K_{\mathrm{d}}$, obtained from the slope and vertical intercept of the plot are listed in Tables 2 and 4.

This calorimetric-based method described recently allows us to obtain the number of binding sites $(g)$, the molar enthalpy of binding site $\left(\Delta H_{\text {bin }}\right)$, and the dissociation equilibrium constant $\left(K_{\mathrm{d}}\right)$ for a set of biomacromolecule binding sites. If no value for $q_{\text {max }}$ yields 
Table 4 Binding parameters for $\mathrm{Fe}^{3+}+\mathrm{CAII}$ interactions via Eq. 1. A value of $p=1$ indicates that $\mathrm{Fe}^{3+}$ binding to CAII is non-cooperative. The positive values of $\delta_{\mathrm{B}}^{\theta}$ suggest that specific interactions, defined here as preferential interactions between $\mathrm{Fe}^{3+}$ and the native folded state of CAII, are dominant

\begin{tabular}{lll}
\hline Binding parameters $^{\mathrm{a}}$ & $T=300 \mathrm{~K}$ & $T=310 \mathrm{~K}$ \\
\hline$K_{1} / \mu \mathrm{mol} \cdot \mathrm{L}^{-1}$ & $91.009 \pm 0.002$ & $109.104 \pm 0.002$ \\
$K_{2} / \mu \mathrm{mol} \cdot \mathrm{L}^{-1}$ & $91.009 \pm 0.002$ & $109.104 \pm 0.002$ \\
$K_{3} / \mu \mathrm{mol} \cdot \mathrm{L}^{-1}$ & $91.009 \pm 0.002$ & $109.104 \pm 0.002$ \\
$p$ & $1 \pm 0.04$ & $1 \pm 0.05$ \\
$\delta_{\mathrm{A}}^{\theta}$ & $0.010 \pm 0.002$ & $-0.076 \pm 0.006$ \\
$\delta_{\mathrm{B}}^{\theta}$ & $3.900 \pm 0.027$ & $3.532 \pm 0.023$ \\
$\Delta H_{\mathrm{max}} / \mathrm{kJ} \cdot \mathrm{mol}^{-1}$ & $-47.335 \pm 0.050$ & $-46.337 \pm 0.062$ \\
$g$ & 3 & 3 \\
\hline
\end{tabular}

a Values of $K_{1}, K_{2}$, and $K_{3}$ were assumed to be the same

Fig. 5 Comparison between the experimental Gibbs energies at $300 \mathrm{~K}(\mathbf{\Delta})$ and $310 \mathrm{~K}(\Delta)$ for $\mathrm{Fe}^{3+}+\mathrm{CAII}$ interactions and calculated results (lines) via Eqs. 7 and 8; mM denotes concentrations in units of mmol. $\mathrm{L}^{-1}$. The linearity of $\Delta G$ against $\mathrm{Fe}^{3+}$ concentrations at lower concentrations indicates that structural effects compensate each other in the Gibbs energy, which supports the extended solvation model

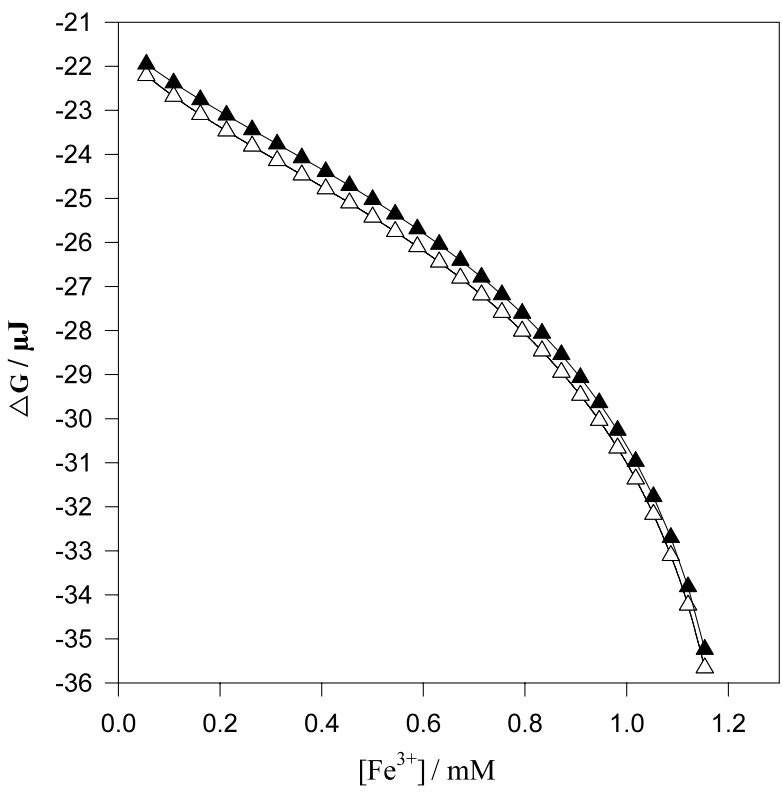

a linear plot of $\left(\Delta q / q_{\max }\right) \mathrm{M}_{0}$ versus $(\Delta q / q) \mathrm{L}_{0}$, then this may be attributed to the existence of non-identical binding sites or the interaction between them. Using this method shows that there are three identical and non-interacting binding sites for $\mathrm{Co}(\mathrm{II})$ ions.

Binding parameters for $\mathrm{Co}^{2+}+\mathrm{CAII}$ and $\mathrm{Fe}^{3+}+\mathrm{CAII}$ interactions, based on the extended solvation model, are listed in Tables 2 and 4 . Similar values for $K_{\mathrm{d}}$ at all three identical binding sites points toward specific interactions between CAII and $\mathrm{Co}^{2+}$ or $\mathrm{Fe}^{3+}$ ions. Values of $\delta_{\mathrm{A}}^{\theta}$ value derived from Eq. 1 suggests that there are no significant changes in the CAII structure due to interaction with $\mathrm{Co}^{2+}$ or $\mathrm{Fe}^{3+}$ ions when the concentration of metal ions is low. At high concentrations of $\mathrm{Co}^{2+}$ or $\mathrm{Fe}^{3+}$ ions, the positive value of $\delta_{\mathrm{B}}^{\theta}$ (Tables 2 and 4) reflect stabilization of the CAII structure. The values $p=1$ found for both systems show the overall non-cooperativity for the interaction of $\mathrm{Co}^{2+}$ and $\mathrm{Fe}^{3+}$ ions with CAII, and include 
Fig. 6 Comparison of the experimental entropies at $300 \mathrm{~K}$ $(\Delta)$ and $310 \mathrm{~K}(\Delta)$ for $\mathrm{Fe}^{3+}+$ CAII interactions and calculated results (lines) via Eqs. 7 and 8; $\mathrm{mmol} \cdot \mathrm{L}^{-1}$ denotes concentrations in units or $\mathrm{mmol} \cdot \mathrm{L}^{-1}$

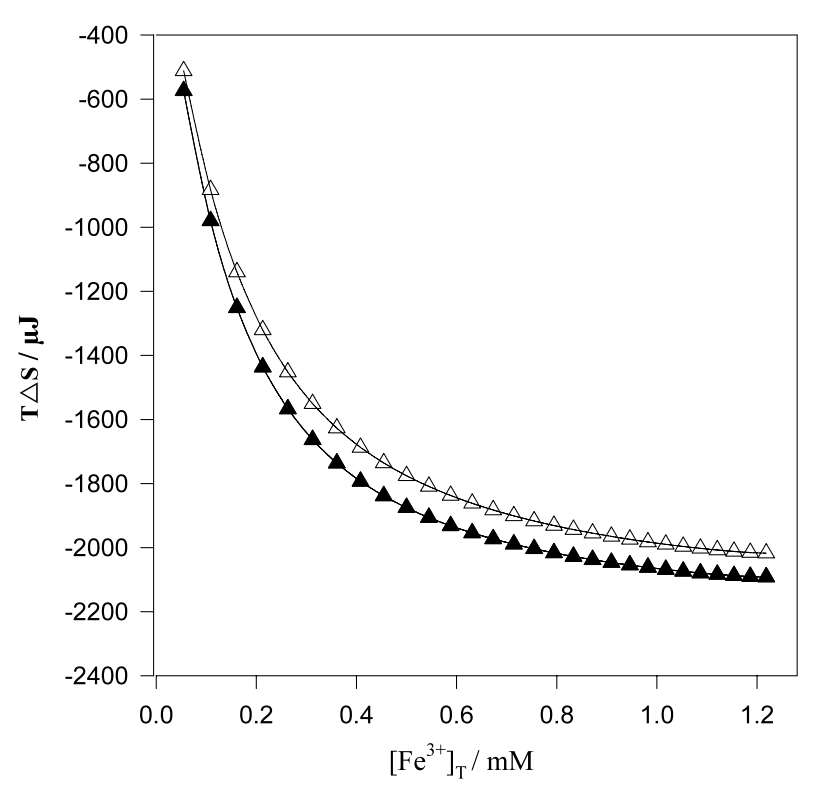

specific and non-specific interactions. These results are consistent with association equilibria resulting from specific interactions at three identical and non-interacting binding sites on CAII $\left(K_{1}=K_{2}=K_{3}=87.150 \mu \mathrm{mol} \cdot \mathrm{L}^{-1}\right)$, underlying the existence of some partially unfolded intermediate forms of CAII that form $\mathrm{Co}^{2+}+\mathrm{CAII}$ and $\mathrm{Fe}^{3+}+\mathrm{CAII}$ complexes. The positive values of $\delta_{\mathrm{B}}^{\theta}$ imply that specific interactions, defined here as preferential interactions between $\mathrm{Co}^{2+}$ or $\mathrm{Fe}^{3+}$ ions and the native folded state of CAII, are present and dominant. The $\delta_{\mathrm{B}}^{\theta}$ values suggest that $\mathrm{Co}^{2+}$ and $\mathrm{Fe}^{3+}$ ions play important roles in the folding of the CAII molecule. Values of $\delta_{\mathrm{B}}^{\theta}$ for the $\mathrm{Fe}^{3+}+$ CAII complex are larger than those of $\mathrm{Co}^{2+}+$ CAII (Tables 2 and 4), implying that the stability of $\mathrm{Fe}^{3+}+$ CAII complexes is greater than for $\mathrm{Co}^{2+}+$ CAII complexes. In $\mathrm{Co}^{2+}+$ CAII and $\mathrm{Fe}^{3+}+$ CAII interactions, either the chemical bonds become stronger or chemical bonds are being formed throughout the interactions that result in negative $\Delta H$ values. At the same time, this act of forming or even strengthening of a bond restricts the movement of the molecule (its ability to rotate, vibrate, etc.) and hence decreases the CAII molecule's entropy. The relatively small negative $\Delta G$ values (Figs. 2 and 5) are consistent with the above interpretations. Carbonic anhydrase is a metalloenzyme containing $\mathrm{Zn}^{2+}$. This metal, which is involved in the biologically active site, can be removed and replaced with other bivalent metal ions. When $\mathrm{Co}^{2+}$ is substituted for the native $\mathrm{Zn}^{2+}$, the enzyme activity is substantially preserved [13], which is in agreement with our results.

Open Access This article is distributed under the terms of the Creative Commons Attribution Noncommercial License which permits any noncommercial use, distribution, and reproduction in any medium, provided the original author(s) and source are credited.

\section{References}

1. Orioli, P.: Structural studies on the interactions between metal ions and biological molecules. Croat. Chem. Acta 71, 659-672 (1998) 
2. Barrese, A.A., Caroli Genis, S., Zoe, F.: Inhibition of carbonic anhydrase II by thioxolone: a mechanistic and structural study. Biochemistry 47, 3174-3184 (2008)

3. Sarraf, N.S., Saboury, A.A., Ranjbar, B., Moosavi-Movahedi, A.A.: Structural and functional changes of bovine carbonic anhydrase as a consequence of temperature. Acta Biochem. Polonica 51, 665-671 (2004)

4. Selma, I., Sinan, S., Cakir, U., Bulut, M., Arslan, O., Ozensoy, O.: In vitro inhibition of cytosolic carbonic anhydrases I and II by some new dihydroxycoumarin compounds. J. Enzyme Inhib. Med. Chem. 23, 32-36 (2008)

5. Bertini, I., Lanini, G., Luchinat, C.: Equilibrium species in cobalt(II) carbonic anhydrase. J. Am. Chem. Soc. 105, 5116-5118 (1983)

6. Nyman, P.O., Strid, L., Westermark, G.: Carboxyl-terminal region of human and bovine erythrocyte carbonic anhydrases. Eur. J. Biochem. 6, 172-189 (2005)

7. Winum, J.Y., Rami, M., Montero, J.L., Scozzafava, A., Supuran, C.T.: Carbonic anhydrase IX: a new druggable target for the design of antitumor agents. Med. Res. Rev. 28, 445-463 (2007)

8. Rezaei Behbehani, G., Waghorne, E.W.: A high-performance theory for thermodynamic study of solvation in mixed solvents. Thermochim. Acta 478, 1-5 (2008)

9. Rezaei Behbehani, G., Saboury, A.A., Bagheri, A.F.: A Thermodynamic study on the binding of calcium ion with myelin basic protein. J. Solution Chem. 36, 1311-1320 (2007)

10. Rezaei Behbehani, G., Saboury, A.A., Taleshi, E.: A comparative study of the direct calorimetric determination of the denaturation enthalpy for lysozyme in sodium dodecyl sulfate and dodecyltrimethylammonium bromide solutions. J. Solution Chem. 37, 619-629 (2008)

11. Rezaei Behbehani, G., Saboury, A.A., Taleshi, E.: Determination of partial unfolding enthalpy for lysozyme upon interaction with dodecyltrimethylammoniumbromide using an extended solvation model. J. Mol. Recognit. 21, 132-135 (2008)

12. Rezaei-Behbehani, G., Saboury, A.A., Gheibi, N.: A new approach for thermodynamic study on binding some metal ions with human growth hormone. J. Solution Chem. 37, 1645-1655 (2008)

13. Bertini, I., Luchinat, C., Scozzafava, A.: Interaction of cobalt(II) bovine carbonic anhydrase with aniline, benzoate and anthranilate. J. Am. Chem. Soc. 99, 581-584 (1977) 